\title{
ANTHROPOMETRIC AND MOTOR PERFORMAMCE CHARACTERISTICS OF MALE SOCCER PLAYERS IN PUBLLC UNIVERSITIES
}

\author{
Timothy K. Mensah, 1, A, B, C, D, E, F Monday O. Moses, 2, A, B, C, D, E, F \\ Charles Domfeh $1, A, B, C, D, E, F$ \\ 1 University of Cape Coast, College of Education Studies \\ Faculty of Science and Technology Education, Department of Health \\ Physical Education and Recreation, Ghana \\ ${ }^{2}$ Kwame Nkrumah University of Science and Technology \\ College of Health Sciences, Faculty of Allied Health Sciences \\ Department of Physiotherapy and Sports Science, Ghana

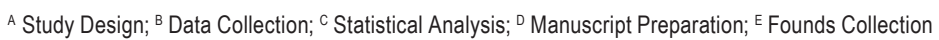 \\ Address for correspondence: \\ Monday Omoniyi Moses \\ Kwame Nkrumah University of Science and Technology, College of Health Sciences \\ Faculty of Allied Health Sciences, Department of Physiotherapy and Sports Science \\ Accra Road, Zip Code: 00000, Private Mail Bag, University Post Office \\ KNUST-Kumasi, Ghana \\ E-mail:momoses@knust.edu.gh
}

Ahstract Background: Training of athletes for optimal performance would be enhanced in an environment of appropriate data. There is, however, limited data on anthropometric and sport performance characteristics of male soccer players in Ghanaian public universities. This study comparatively presents the distribution of anthropometric and motor performance characteristics of male soccer players among public universities.

Methods: Male soccer players ( $n=44$, mean age $=22.61 \pm 1.87 \mathrm{yrs}$ ) from four public universities were recruited. Weight, leg length, thigh girth, calf girth, forearm length, upper arm length, upper arm girth, chest girth, and finger span were measured. The participants were also assessed on a $36.58 \mathrm{~m}$ (40 yards) dash, vertical jump, agility, flexibility, sit-ups, push-ups, dribbling, shooting accuracy, and kicking distance.

Results: There were significant differences in the forearm length $(p=0.001)$, leg power $(p=0.040)$, abdominal strength $(p=0.005)$, agility $(p=0.001)$, flexibility $(p=0.009)$, and upper body strength $(p=0.023)$ among the male soccer players of the universities. All anthropometric characteristics significantly predicted kicking distance $(p=0.002)$. Thigh girth $(p=0.014)$, chest girth $(p=0.010)$ and finger span $(p=0.012)$ significantly distinctly served as predictors.

Conclusion: Anthropometric and motor performance characteristics were relatively different among male soccer players in Ghana public universities. University soccer coaches should place major emphasis on individual traits and potentials when developing combined training regimes.

Key Wordls arm length and girth, chest girth, finger span, muscular strength, kicking abilities 


\section{Introduction}

In Ghana universities, soccer is an integral part of the total educational system and is used as a co-curricular activity. Thus, among the universities in Ghana, soccer is a pervasive tool to develop students for future goals (Acquah, Anti-Partey, 2014). Organized competitive soccer in the tertiary institutions in Ghana, especially in the universities, is played intramurally (inter-hall and inter- faculty games) and extramurally, which include interuniversity competitions such as Ghana University Sports Association (GUSA) games. International competitions in which universities in Ghana participate in soccer are the West Africa University Games (WAUG), Federation of Africa University Sports (FASU) games and International University Sports Federation (FISU) games.

Soccer players at the university level, chiefly those who represent their university or the National Federation at national and international levels, are anticipated to possess the physical and physiological qualities, namely physique, stature, speed, agility, muscular and general strength, high skill level, endurance and coordination, that are needed to excel in that sport. Anthropometric and motor performance characteristics contribute chiefly to the supremacy of players and team performances in soccer (Chiwaridzo et al., 2017; Deprez et al., 2015; Loturco et al., 2018) aside from nutrition (Baker, Rollo, Stein, Jeukendrup, 2015) and psyche status (Baker et al., 2015).

These are scientifically proven aspects of modern competitive soccer (Baloncesto, 2019; Chiwaridzo et al., 2017; Saha, Nandy, Bandyopadhyay, 2018). However, these phenomena have not been established currently in competitive soccer in Ghana. As such, there is a dearth of general literature on anthropometric and motor performance characteristics in Ghana sports in general. This situation is no different from what pertains in the public universities in Ghana which are the citadel of knowledge. Therefore, just like any other coach in Ghana, the coaches in these universities use the soccer players as they come into the universities and select them based on the impressions the players make on the field of play, or on the suggestions the players give to the coaches. This is non-scientific as explained earlier, and certainly it hinders the optimal performance and full potential of the players, even though they might have been exerting their maximum efforts. As such, the modern-day competitive soccer coach is expected to have and always update a database of these characteristics of the players to be able to compare them to their opponents for possible tactical play. Also, sport development at the universities would rely largely on appropriate available data. Certainly, because of limited data, particularly in the public universities in Ghana, university coaches go through herculean tasks in pitching quality, fit and healthy players for competitions which always yield minimal results. Thus, the need to assess these characteristics in male soccer players at public universities and compare by institution to discover their major differences and challenges and make recommendations for necessary improvements.

\section{Material and Methods}

\section{Research Design}

A cross-sectional descriptive research design was employed to measure and describe the anthropometric and motor performance characteristics of the soccer players who participated in the 6th Mini GUSA Games, in line with scholarly standards (Moutinho, Hutcheson, 2011; Spector, 2019). 


\section{Participants}

The participants consisted of the male soccer players from seven public universities - UG, KNUST, UCC, UEW, UDS, UENR and UPSA, who represented their universities at the 6th mini GUSA games hosted by Kwame Nkrumah University of Science and Technology (KNUST), where institutions were allowed to present up to 20 players each. A total pool of 140 male soccer players were involved in the 6th Mini GUSA competitions.

Four out of the seven public universities in Ghana, namely KNUST, UEW, UG and UCC, who participated in the 6th Mini GUSA games were intentionally sampled for the study as they had been consistently present and had played in the semi-finals of the GUSA games since its inception. The 11 players that made the first teams, which included 1 or 2 striker(s), 4 or 5 midfielders (depending on the strategies of the coaches), 4 defenders (2 laterals and 2 centrals) and 1 goalkeeper, were again intentionally selected from each institution for the study because some of the reserved players did not get the chance to play at all at the games, and therefore the possibility of chancing on those players were eliminated. Consequently, a total of 44 male soccer players were enrolled in the study.

\section{Measurements}

To ensure that the participants recorded their best performances at each test, 5 -minute intervals were allowed between the tests. All the tests were arranged in such a way that the preceding test could not interfere with the next. The following order of arrangements were followed:

Stage 1: Weight $(\mathrm{kg})$ was measured with a Camry ISO 9001 Model digital portable scale (Japan), height (cm) was measured with a calibrated stadiometer from $5.0 \mathrm{~cm}$ to $2.5 \mathrm{~cm}$, leg length (fall), mid-thigh girth (flexed and tensed), calf girth, upper arm length, forearm length, upper arm girth, chest girth, and finger span were measured in accordance to international standards (Bretzin, Mansell, Tierney, McDevitt, 2017).

Stage 2: Speed (36.58 m [40 yard] dash), leg power (vertical jumps), upper body strength (push-ups), and kicking ability (distant kick, dribbling and accuracy) were determined with a Quantum stop watch. Sayers Formula [Peak Anaerobic Power output-PAPw (Watts) $=60.7 \times$ jump height $(\mathrm{cm})+45.3 \times$ body mass $(\mathrm{kg})-2055$ ] was used to estimate peak power output from vertical jumps (Sayers, Harackiewicz, Harman, Frykman, Rosenstein, 1999).

Stage 3: Agility (Illinois run), abdominal strength (sit ups), and flexibility test (sit and reach test).

All the anthropometric measurements, agility test, body strength tests, flexibility and vertical jump, were carried out at the gymnasium and fitness hubs of the various universities, whilst the rest of the physical performance tests, which included throwing, kicking, dribbling and sprint tests, took place on the soccer fields and athletic ovals, respectively. The data collection began at UCC on the 23rd February 2016, followed by UEW on the 24th of February 2016. UG was next on the 25th February, followed by KNUST on the 27th of February 2016.

Kicking Ability: Participants kicked aerial balls in three trials as far as possible from the goal line. The distance to where the ball landed was measured to the nearest $0.1 \mathrm{~m}$ with a tape measure. Dribbling was measured with a stop watch in seconds. Procedure: With a whistle and concurrently starting the stop watch, participants started zigzag dribbling with a ball between six cones, then moved forward $3 \mathrm{~m}$, took a right turn, dribbled straight for $5 \mathrm{~m}$ through 4 cones and again took another right turn and dribbled the ball $5 \mathrm{~m}$ through 5 cones back to the restraining line. The time taken to complete the course to the nearest 0.1 second was recorded and the average of three trails considered as the score (Ghosh, Goon, 2014; Longmuir et al., 2017; Pfeiffer et al., 2020). Shooting for accuracy was measured in points. The goal post was divided into 5 equal parts and labelled with a point system of 5 for the extremes which reduced towards the center to 3 points. The participant kicked the ball from the penalty spot 
and scored points according to the target they hit (Ghosh, Goon, 2014). The total points of all the three trials were recorded and the average used as the score

\section{Statistical Analysis}

The data collected were analyzed using IBM SPSS Statistics Data Editor. Both descriptive and inferential statistics were employed to analyze the data collected. Descriptive statistics was used to compile the means and standard deviations (SD) of the players for demographic analysis in all the variables. One-way analysis of variance (ANOVA) was employed to compare player characteristics between the four institutions (A-D). Bonferroni post-hoc multiple comparison tests were applied when the ANOVA indicated significant differences, to ascertain the exact differences that existed between the means. Multiple regression analysis was used to analyze the influence of the anthropometric and motor performance variables on the kicking ability. The alpha level was set at 0.05 .

\section{Results}

The male soccer players of the four Ghana public universities had a mean height of $174.44 \pm 5.40 \mathrm{~cm}$, weight of $73.39 \pm 5.60 \mathrm{~kg}$, leg length of $86.51 \pm 5.55 \mathrm{~cm}$, thigh girth of $58.55 \pm 3.42 \mathrm{~cm}$, calf girth of $38.76 \pm 1.75 \mathrm{~cm}$, upper arm length of $38.23 \pm 2.64 \mathrm{~cm}$, forearm length of $31.71 \pm 2.69 \mathrm{~cm}$, upper arm girth of $30.48 \pm 1.46 \mathrm{~cm}$, chest girth of $88.75 \pm 1.33 \mathrm{~cm}$, and finger span of $58.03 \pm 4.55 \mathrm{~cm}$. The participants ran $36.58 \mathrm{~m}$ (40 yards) in $5.28 \pm 0.22 \mathrm{sec}$ on average, generated $4407.76 \pm 7.23$ Watts of leg power, performed $26.46 \pm 2.44 \mathrm{reps} / \mathrm{min}$ in abdominal strength, ran the Illinois agility course in $16.32 \pm 0.63$ secs, executed flexibility on average at $25.67 \pm 3.04 \mathrm{~cm}$ and 30.43 \pm 3.79 reps in upper body movement. On kicking ability, the participants were able to kick the ball a mean distance of $56.94 \pm 7.44 \mathrm{~m}$, mean mark for dribbling was $14.71 \pm 1.04$ secs and kicking accuracy was $4.09 \pm 1.29$ points (Table 1). A significant regression was found $F(3.40)=3.623, p<0.05$ with $R^{2}$ of 0.523 which translates into $52.3 \%$ of anthropometric variance in kicking distance for the soccer players in the GUSA games (Table 2).

Table 1. Differences in anthropometric and motor performance characteristics of male Soccer Players among Institutions

\begin{tabular}{|c|c|c|c|c|c|c|}
\hline \multirow[b]{2}{*}{ Characteristics } & \multicolumn{4}{|c|}{ Institutions } & \multicolumn{2}{|c|}{ ANOVA } \\
\hline & $\begin{array}{l}\text { University A } \\
\text { Mean, SD }\end{array}$ & $\begin{array}{c}\text { University B } \\
\text { Mean, SD }\end{array}$ & $\begin{array}{c}\text { University C } \\
\text { Mean, SD }\end{array}$ & $\begin{array}{c}\text { University D } \\
\text { Mean, SD }\end{array}$ & $\mathrm{F}$ & P-value \\
\hline 1 & 2 & 3 & 4 & 5 & 6 & 7 \\
\hline \multicolumn{7}{|c|}{ General } \\
\hline Height $(\mathrm{cm})$ & $177.86,3.82$ & $172.99,6.32$ & $172.75,5.83$ & $174.16,4.33$ & 2.287 & 0.093 \\
\hline Weight (kg) & $75.60,5.32$ & $72.99,5.59$ & $72.38,6.44$ & $72.58,5.13$ & 0.774 & 0.516 \\
\hline \multicolumn{7}{|c|}{ Anthropometry } \\
\hline Leg length (cm) & $87.72,2.48$ & $83.34,9.87$ & $87.22,2.91$ & $87.78,2.33$ & 1.707 & 0.181 \\
\hline Thigh girth (cm) & $60.55,4.08$ & $58.53,3.38$ & $57.99,3.11$ & $57.13,2.40$ & 2.132 & 0.111 \\
\hline Calf girth $(\mathrm{cm})$ & $39.78,1.26$ & $38.66,1.92$ & $38.59,1.68$ & $38.00,1.79$ & 2.127 & 0.112 \\
\hline Upper arm length $(\mathrm{cm})$ & $39.29,2.45$ & $38.28,2.68$ & $37.69,3.28$ & $37.66,2.00$ & 0.913 & 0.443 \\
\hline Forearm length $(\mathrm{cm})$ & $34.36,2.83^{*}$ & $30.40,2.38^{*}$ & $30.50,1.93^{*}$ & $31.74,1.09^{*}$ & 8.032 & $0.001 \dagger$ \\
\hline Upper arm girth (cm) & $31.00,1.80$ & $29.85,1.29$ & $30.49,1.37$ & $30.57,1.30$ & 1.183 & 0.328 \\
\hline Chest girth $(\mathrm{cm})$ & $88.66,1.33$ & $87.44,3.52$ & $90.53,3.04$ & $88.39,2.98$ & 2.279 & 0.094 \\
\hline Finger span $(\mathrm{cm})$ & $57.63,5.85$ & $58.28,3.83$ & $57.56,4.74$ & $58.66,4.10$ & 0.139 & 0.936 \\
\hline
\end{tabular}




\begin{tabular}{lcccccc}
\hline \multicolumn{1}{c}{1} & 2 & 3 & 4 & 5 & 6 & 7 \\
\hline Speed (sec.) & \multicolumn{5}{c}{ Motor Performance } \\
Leg power (Watts) & $5.14,0.11$ & $5.30,0.25$ & $5.33,0.23$ & $5.37,0.23$ & 2.601 & 0.065 \\
Abdominal strength (rep./min) & $4,224.78,5.37^{*}$ & $4,693.04,5.79^{*}$ & $4,438.49,8.22$ & $4,273.33,6.80$ & 3.032 & $0.040 \dagger$ \\
Agility (sec.) & $27.64,1.86^{*}$ & $26.09,2.12$ & $27.55,2.77^{*}$ & $24.55,1.75^{*}$ & 4.994 & $0.005 \dagger$ \\
Flexibility (cm) & $16.59,0.41^{*}$ & $16.35,0.32^{*}$ & $15.68,0.84^{*}$ & $16.65,0.32^{*}$ & 8.063 & $0.001 \dagger$ \\
Upper body strength (rep./min) & $28.16,2.71^{*}$ & $24.13,2.12^{*}$ & $25.16,3.25$ & $25.24,2.74$ & 4.429 & $0.009 \dagger$ \\
Distant kick (m) & $30.64,1.80$ & $29.55,2.16$ & $33.09,5.68^{*}$ & $28.46,2.91^{*}$ & 3.557 & $0.023 \dagger$ \\
Dribbling (sec.) & $56.82,8.91$ & $55.32,6.42$ & $60.32,6.36$ & $55.32,7.66$ & 1.115 & 0.354 \\
Kicking accuracy (pt.) & $14.96,1.37$ & $14.72,0.94$ & $14.46,0.85$ & $14.71,1.01$ & 0.414 & 0.744 \\
\hline
\end{tabular}

$\dagger$ Significance difference in ANOVA at $P<0.05$.

${ }^{*}$ The Bonferroni post hoc test significant at $\mathrm{P}<0.05$.

Table 2. Multiple regression analysis between Anthropometric Characteristics on Kicking Ability

\begin{tabular}{lcccc}
\hline \multicolumn{1}{c}{ Characteristics } & $B$ & $\beta$ & T-value & P-value \\
& 7.212 & & -0.820 & $0.002^{*}$ \\
\hline Height $(\mathrm{cm})$ & -0.652 & -0.473 & -1.385 & 0.175 \\
Weight $(\mathrm{kg})$ & 0.084 & 0.063 & 0.268 & 0.791 \\
Leg length $(\mathrm{cm})$ & 0.162 & 0.121 & 0.783 & 0.439 \\
Thigh girth $(\mathrm{cm})$ & 1.407 & 0.647 & 2.598 & $0.014^{*}$ \\
Calf girth & -0.329 & -0.077 & -0.346 & 0.731 \\
Upperarm length $(\mathrm{cm})$ & -1.090 & -0.386 & -1.518 & 0.138 \\
Forearm length $(\mathrm{cm})$ & 0.649 & 0.234 & 1.188 & 0.243 \\
Upperarm girth $(\mathrm{cm})$ & -0.233 & -0.046 & -0.264 & 0.793 \\
Chest girth $(\mathrm{cm})$ & 1.231 & 0.491 & 2.606 & $0.010^{*}$ \\
Finger span $(\mathrm{cm})$ & 0.613 & 0.375 & 2.649 & $0.012^{*}$ \\
\hline
\end{tabular}

* Significant at $P<0.05, R=0.723, R^{2}=0.523, \mathrm{~F}=3.623$.

Significant regression was found $F(3,40)=3.623, p<0.05$ with $R^{2}$ of 0.523 that translates into $52.3 \%$ of variance as anthropometric variables model in the kicking for distance of the soccer players in GUSA games.

\section{Discussion}

This study comparatively presents the distribution of anthropometric and motor performance characteristics of male soccer players in public universities. Findings generally revealed differences in all the characteristics, while some predicted several motor performance characteristics.

\section{Anthropometric}

The mean height of the male soccer players in the GUSA games was not significantly different, although height favored the soccer players from the universities of Ghana comparatively. This indicates that the male soccer players of these public universities had relatively the same height. Holding other parameters constant, the equality in height probably explains why there were very few aerial header goals (less than 5) emanating from the 6th Mini GUSA games. This is in consonance with literature reports that height advantageously enhances excellent performance in sports that require aerial vertical height activities such as handball, rugby and soccer (Bidaurrazaga-Letona, 
Zubero, Lekue, Amado, Gil, 2016; Reilly, Williams, Nevill, Franks, 2000). However, the mean height recorded in this study was less than the values reported for collegiate male soccer players (Lockie et al., 2019; Slimani, Nikolaidis, 2019), indicating that the players in this study would be disadvantaged in height at international competition.

According to the findings of this study, there was no significant difference in the weight of the public university male soccer players. Perhaps, this explains why these teams may not have had too much advantage over each other in activities such as charging for the ball. Coaches probably resorted to tactical disciplines to marginally win or draw their matches. This sounds in keeping with earlier viewpoints that larger and heavier athletes typically produce greater absolute strength, power and with similar advantages than smaller athletes (Bale, Colley, Mayhew, Piper, Ware, 1994; Domfeh, 2002). Although, the mean weight in this study was more than the values reported for similar regional population samples (Moses, Duduyemi, 2016; Saha, Kundu, Mondal, 2014) but less than international values of similar studies (Anding, Oliver, 2015; Kilic, Ali, Tosur, 2018). This signifies that the players in this study could have been within limits with weight-related activities but could have been disadvantaged at international competitions.

With regards to the length of the lower extremities (leg length), there was no statistically significant difference in the soccer players in the present study. Similar geographical location and heredity ar e some of the possible interpretations of the non-significant differences observed in this study. The anatomical advantage in favor of long legs creates a better opportunity for competitive soccer performance where vertical height is required (Duarte et al., 2016; Lloy, Oliver, Myer, Croix, Read, 2020). However, this similarity in leg length may be a determinant factor behind the players equally kicking the ball for distance with no undue advantage (Malekar, 2015).

There were also no significant differences in the thigh and calf girths of these soccer players. However, the mean thigh girth $(58.55 \pm 3.42 \mathrm{~cm})$ and calf girth $(38.76 \pm 1.75 \mathrm{~cm})$ compared favorably with the values reported for basketball (595.95 $\pm 39.87 / 385.90 \pm 33.44 \mathrm{~mm})$, handball $(592.14 \pm 82.99 / 390.63 \pm 27.64 \mathrm{~mm})$, and football $(609.64$ $\pm 30.48 / 395.84 \pm 23.09 \mathrm{~mm}$ ) players (Baloncesto, 2019), although better than the values for young elite soccer players (Rodríguez-Lorenzo, Olmo, Sánchez-Molina, Martín-Acero, 2018). Large thigh and calf circumferences are often associated with training and muscular strength development, since specific strength training predisposes to hypertrophy of the lower limb muscles (Baloncesto, 2019; Carvalho, Abade, 2014). Calf and thigh girths have correlations with dribbling and kicking distance (Gosh, Goon, 2014; Nuhmani, Akthar, 2014; Wilson et al., 2017; Sylejmani et al., 2019). Thus, the insignificant differences found could also possibly be some of the contributing reasons for the equality in the kicking distance as well as dribbling with no unjustified advantage. The winner of the 6th Mini GUSA games may have resorted to other parameters in their favor to win the contest.

The results of the present study also showed no significant differences in the upper arm length, upper arm girth, chest girth and finger span of soccer players among these public universities, against a significant difference in forearm length. The institution that was favored with forearm length may certainly have had an edge over the rest with throw-ins and their goalkeeper reaching for the ball. In explaining this, studies affirmed that longer arms can help throw a ball faster and further due to the increased centrifugal force they can generate during the throwing motion (Marshall, Hamstra-Wright, Dick, Grove, Agel, 2007; Omar, 2016; Naito, Takagi, Kubota, Maruyama, 2017). This is similar to a ball at the end of a string, the longer the string, the further it can go after release. The findings of our study have a direct comparison with studies where similar characteristics were observed (Hooda, 2015; Saha et al., 2018). 


\section{Motop Performance}

There was a statistically insignificant difference in the speed performance of soccer players in the public universities. This outcome supports a study that compared vertical jump ability (squat-jump [SJ] and counter movement-jump [CMJ]), mean propulsive power in the jump-squat (MPP-REL JS) relative to body mass, and the $0-5,5-10$, and 10-20 $\mathrm{m}$ acceleration and speed among soccer players from the same professional club, divided into age-categories (U15 [n=20], U17 [n = 53], U20 [n=22] and senior $[n=25]$ players) with no significant differences (Loturco et al., 2018). However, the average speed performance in our study where soccer players ran $36.58 \mathrm{~m}$ (40 yards) in $5.28 \pm .22 \mathrm{sec}$ was comparatively better than earlier finding in a similar population where $30 \mathrm{~m}$ was run in $5.99 \pm 0.15 \mathrm{sec}$ (Coelho et al., 2007). These results probably also explain why there were not many goals scored between these institutions because the attackers' ability to outpace the defenders and vice versa were similar, which underpinned their successful game play (Murphy, Pill, 2011; Little, Williams, 2005; Peñailillo, Espíldora, Jannas-Vela, Mujika, Zbinden-Foncea, 2016; Loturco et al., 2018).

There was a significant difference in leg power between the soccer players in this study. Players from one of the universities were significantly stronger from another university $(p<0.05)$. This outcome supports an earlier report which showed significant differences in explosive leg power growth curves of soccer players across their lifespan (Loturco et al., 2018). This finding suggests variations in leg power of different playing positions and training priority as well as the efficiency of each institution. Dissimilar movement strategies of the limbs and playing in different positions required different skills from players, where "strikers jump higher than midfielders or defenders, and strikers develop greater power in the legs compared to midfielders" (Sportu, Nikolaidis, 2018), could support our results. The study by D.W. Malekar (2015) reported a high correlation between leg power and kicking distance, which was not the case with the players with the highest leg power in this study. This may probably be due to other confounding parameters.

In abdominal strength, players of two universities significantly performed better than the least performance. This indicates that players with the best abdominal strength from the two universities had stronger spine stability and were able to experience better prevention of low back pain compared to the others. A study has shown that the abdominal muscles, hip and back muscles are accountable for enhancing posture, executing movements, regulating muscular activities, ensuring stability and stabilizing strength throughout the body (Aslan, Erkmen, Aktaş, Güven, 2018). A.K. Aslan et al. (2018) further reiterated that core stability permits a concurrent growth of arm and leg strength, with increased movement efficiency and power generation. The team with the strongest abdomen, which also may have accounted for their being very agile (Malekar, 2015), were the eventual winners of the competition.

Although significant differences occurred in the agility performances of the players in this study, players from three universities had relatively similar and/or the same level of performance. This implies that most of the players had relatively equal potential in the ability to exhibit the two components of agility - the ability to change direction as well as perceptual and decision making ability, as presented in the literature (Zouhal et al., 2018). The highest performing team which created a significant difference in this task probably used it to their advantage to outwit their opponents to win the contest.

The results again showed significant differences observed in the flexibility of the lower back and hamstring muscles of the winning team and the rest $(28.16 \pm 2.71 \mathrm{~cm}$ and $24.13 \pm 2.12 \mathrm{~cm})$. Differences in pre-competition stretching and warm-ups may contribute to this result because studies have shown that a pre-exercise period of stretching exercises can acutely increase flexibility (Ide et al., 2017). Non-significant differences obtained from 
the players of the remaining universities supports an earlier finding of no significant differences in flexibility of the hip joint between the preferred and non-preferred leg (Rahnama, Lees, Bambaecichi, 2005). A common rationale supporting the increase in range of motion at a joint reported in literature is to prevent injury from overextension of the joint, such as a pulled muscle (Rodriguez, Sanchez, Rodriguez, Villa, 2016; Opplert, Babault, 2018). Indeed, there were a lot of injuries in the team that was least flexible.

Our result on upper body strength showed that players of one university possessed a significantly higher value, and another possessed a significantly lower performance. The effect of years of training may possibly be an explanation for the differences in the upper body strength of soccer players between the two universities (Bilsborough et al., 2015). This is because the university which has most of their soccer players in their final academic year would have relatively more than three training years together compared to those with most players in years one or two. Indeed, the university that won the competition had most of their players in the final year. This also implies that the players of the winning team may have had an advantage of power for the throw-in, run and charge in the games than the rest, as explained by T. Bompa and G.G. Haff (2009) and C. Domfeh (1996).

A notable finding of the present study is the lack of significant differences in kicking distance, dribbling ability and kicking accuracy. We expected diverse performances based on the training principles and ideologies of the coaches. We also envisaged cognitive and biomechanical traits associated with academic training. Students from different academic disciplines should exhibit an appreciable transfer of theoretical knowledge when performing common sport skills. Irrespective of playing position, a desirable kicking distance, dribbling ability and kicking accuracy are inevitable skills of soccer players (Gaspar et al., 2019).

The motor performance characteristics examined in this study were significantly predicted by the anthropometric characteristics, specifically the thigh girth, chest girth and finger span of the soccer players (Table 2). This may be explained in the view of the major influence of training efficiency and heredity, since growth and maturity play effective roles in sport performances (Bilsborough et al., 2015; Gaspar et al., 2019; Guimar et al., 2019).

As stated earlier, the proven scientific ideology behind the placement of players, vis-à-vis their anthropometric and motor performance characteristics, generally did not matter to most coaches during these games (6th Mini GUSA Games), with the exception of one (UCC). We believe the coaches of UCC paid some attention to these technical abilities of their players for each position and the tactics which aided them in winning the entire tournament, as most of the observed significant differences were in their favor. For instance, significant differences that existed in abdominal strength, agility and upper body strength were all in their favor, which must have given them supremacy in moving the ball and charging during attacks and defenses (Bompa, Haff, 2009; Domfeh, 1996).

\section{Conclusions}

There were significant differences in the forearm length, leg power, abdominal strength, agility, flexibility and upper body strength between public university male soccer players in Ghana.

Thigh girth, chest girth and finger span significantly influenced the kicking ability (kicking distance and dribbling) of male soccer players in the GUSA games. The forearm length, leg power, abdominal strength, agility, flexibility and upper body strength of the male soccer players were also the basis for differences in performances. The anthropometric characteristics, agility and flexibility of the male soccer players influenced their kicking abilities. 


\section{References}

Acquah, B., Anti-Partey, P. (2014). The influence of co-curricular activities on students' performance in economics. Journal of Educational Management, 6, 147-160.

Anding, R., Oliver, J.M. (2015). Football Player Body Composition: Importance of Monitoring for Performance and Health. Sports Science Exchange, 28 (145), 1-8.

Aslan, A.K., Erkmen, N., Aktaş, S., Güven, F. (2018). Postural Control and Functional Performance after Core Training in Young Soccer Players. Malaysian Journal of Movement, Health \& Exercise, 7 (2), 23-38.

Baker, L.B., Rollo, I., Stein, K.W., Jeukendrup, A.E. (2015). Acute Effects of Carbohydrate Supplementation on Intermittent Sports Performance. Nutrients, 7, 5733-5763. DOI: 10.3390/nu7075249.

Bale, P., Colley, E., Mayhew, J., Piper, F., Ware, J. (1994). Anthropometric and somatotype variables related to strength in American football players. Journal of Sports Medicine and Physical Fitness, 34 (4), 142-148.

Baloncesto, D. (2019). Anthropometric and Body Composition Differences Among Elite Kosovo Basketball, Handball and Soccer Players. International Journal of Morphology., 37 (3), 1067-1072.

Bidaurrazaga-Letona, I., Zubero, J., Lekue, J.A., Amado, M., Gil, S.M. (2016). Anthropometry and somatotype of pre-adolescent soccer players: Comparisons amongst elite, sub-elite and non-elite players with non-players. Collegium Antropologicum, 40 (4), 269-277.

Bilsborough, J., Greenway, K., Opar, D., Livingstone, S., Cordy, J., Bird, S., Coutts, A. (2015). Comparison of anthropometry, upperbody strength and lower-body power characteristics in different levels of Australian Football players. The Journal of Strength \& Conditioning Research, 29 (3), 826-834.

Bompa, T., Haff, G.G. (2009). Periodization: Theory and methodology of training; (5 $5^{\text {th }}$ ed). UK, Champaign: Sheridan Books.

Bretzin, A.C., Mansell, J.L., Tierney, R.T., McDevitt, J.K. (2017). Sex Differences in Anthropometrics and Heading Kinematics Among Division I Soccer Athletes: A Pilot Study. Sports Health, 9 (2), 168-173. DOI: 10.1177/1941738116678615.

Carvalho, A., Abade, E. (2014). Effects of Strength Training Combined with Specific Plyometric exercises on body composition, vertical jump height and lower limb strength development in elite male handball players: a case study. Journal of Human Kinetics, 41 (1), 125-132. DOI: 10.2478/hukin-2014-0040.

Chiwaridzo, M., Oorschot, S., Dambi, J.M., Ferguson, G.D., Bonney, E., Mudawarima, T., Tadyanemhandu, C., Smits-Engelsman, B.C. (2017). A systematic review investigating measurement properties of physiological tests in rugby. BMC Sports Science, Medicine and Rehabilitation, 9 (24). DOI: 10.1186/s13102-017-0081-1.

Coelho, D.B., Lúcio, M., Braga, P., Ferreira, P.A., Condessa, L.A., Ávila, L.D., Fleury, C. (2007). Performance of Soccer Players of Different Playing Positions and Nacionalities in A 30-Meter Sprint Test. In: H.-J. Menzel, M.H. Chagas (eds), XXV ISBS Conference Proceedings Archive (pp. 362-365). Seoul: OJS/PKP Publishing House.

Deprez, D., Valente-Dos-Santos, J., Coelho-e-Silva, M.J., Lenoir, M., Philippaerts, R., Vaeyens, R. (2015). Longitudinal Development of Explosive Leg Power from Childhood to Adulthood in Soccer Players. International Journal of Sports Medicine, 36 (8), $672-679$.

Domfeh, C. (1996). Factors responsible for the low performance of western regional teams in the national milo schools and colleges soccer competitions. Unpublished undergraduate project. Cape Coast: University of Cape Coast.

Domfeh, C. (2002). Factors responsible for the inability of the black stars of Ghana to qualify for the world cup soccer tournaments. Cape Coast: University of Cape Coast.

Duarte, J.P., Tavares, Ó., Valente-dos-Santos, J., Severino, V., Ahmed, A., Rebelo-Gonçalves, R., Pereira, J.R., Vaz, V., Póvoas, S., Seabra, A. and Cumming, S.P., (2016). Repeated Dribbling Ability in Young Soccer Players: Reproducibility and Variation by the Competitive Level. Journal of Human Kinetics, 53 (1), 155-166. DOI: 10.1515/hukin-2016-0019.

Gaspar, A., Santos, S., Coutinho, D., Gonçalves, B., Sampaio, J., Leite, N. (2019). Acute effects of differential learning on football kicking performance and in countermovement jump. Plus One, 14 (10), e0224280.

Ghosh, P., Goon, A.K. (2014). A Comparative Study on Physical Variables of Club and Non-Club Cricketers in Kolkata India. International Journal of Physical Education, Fitness and Sports, 4 (1), 71-77.

Guimar, E., Baxter-Jones, A., Maia, J., Fonseca, P., Santos, E., Tavares, F., Ant, M. (2019). The Roles of Growth, Maturation, Physical Fitness, and Technical Skills on Selection for a Portuguese Under-14 Years Basketball Team. Sports (Basel), 7 (3), 1-13. DOI: 10.3390/sports7030061.

Hooda, D. (2015). Comparative study of Anthropometric measurements and body Composition between individual and team game of Punjab University Chandigarh. International Journal of Multidisciplinary Research and Development, 2 (6), 643-646. 
Ide, B.N., Moreira, A., Schoenfeld, B.J., Lodo, L., dos Reis Santos, A., Lopes, C.R., Aoki, M.S. (2017). Acute effect of different warm-up interventions on neuromuscular performance of recreational soccer players. Revista Brasileira de Ciência e Movimento, 25 (3), 34-43. DOI: 10.18511/rbcm.v25i3.7053.

Kilic, T., Ali, M., Tosur, A. (2018). A Comparison of Some Parameters of Football Players According to the Leagues They Play In. Journal of Education and Training Studies, 6 (11), 135-142. DOI: 10.11114/jets.v6i11.3591.

Little, T., Williams, A. (2005). Specificity of acceleration, maximum speed and agility in professional soccer players. In: T. Reilly, J. Cabri, D. Araújo (eds), Science and Football V: The Proceedings of the Fifth World Congress on Sports Science and Football (pp. 289-296). London: Routledge.

Lloy, R.S., Oliver, J.L., Myer, G.D., Croix, M.S., Read, J.P. (2020). Seasonal variation in neuromuscular control in young male soccer players. Physical Therapy in Sport, 42, 33-39.

Lockie, R.G., Moreno, M.R., Orjalo, A.J., Stage, A.A., Liu, T.M., Birmingham-Babauta, S.A., Hurley, J.M., Torne, I.A., Beiley, M.D., Risso, F.G., Davis, D.L. (2019). Repeated-Sprint Ability in Division I Collegiate Male Soccer Players. Journal of Strength and Conditioning Research. DOI: 10.1519/jsc.0000000000001948.

Longmuir, P.E., Boyer, C., Lloyd, M., Borghese, M.M., Knight, E., Saunders, T.J., Boiarskaia, E., Zhu, W., Tremblay, M.S. (2017). Canadian Agility and Movement Skill Assessment (CAMSA): Validity, objectivity, and reliability evidence for children 8-12 years of age. Journal of Sport and Health Science, 6 (2), 231-240. DOI: 10.7717/peerj.8784.

Loturco, I., Jeffreys, I., Kobal, R., Abad, C.C.C., Ramirez-Campillo, R., Zanetti, V., Pereira, L.A. and Nakamura, F.Y. (2018). Acceleration and Speed Performance of Brazilian Elite Soccer Players of Different Age-Categories . Journal of Human Kinetics, 641, 205218. DOI: 10.1515/hukin-2017-0195.

Malekar, D.W. (2015). Relationship of selected anthropometric measurements and strength to kicking ability of soccer players. International Journal of Physical Education, Sports and Health, 1 (4), 120-123.

Marshall, S.W., Hamstra-Wright, K.L., Dick, R., Grove, K.A., Agel, J. (2007). Descriptive epidemiology of collegiate women's softball injuries: National Collegiate Athletic Association Injury Surveillance System, 1988-1989 through 2003-2004. Journal of athletic training, 42 (2), 286-294.

Moses, M., Duduyemi, B. (2016). Sports Participation, Anthropometric and Physiological Profiles of University Athletes. Nigerian Journal of Physiological Sciences, 31 (1), 63-69.

Moutinho, L., Hutcheson, G. (2011). Cross-Sectional Designs. In: L. Moutinho, G. Hutcheson (eds), The SAGE Dictionary of Quantitative Management Research. UK: SAGE Publications Ltd.

Murphy, J., Pill, S. (2011). Moving, Learning and Achieving in Football (Soccer). In: G.D. Dodd (ed.), Proceedings of the 27th ACHPER International Conference on Moving, Learning and Achieving. Prince Alfred College, Adelaide, South Australia, 18-20 April, 2011 (pp. 220-229). Retrieved from: https://ro.uow.edu.au/cgi/viewcontent.cgi?article=1672\&context=edupapers\#page=234 (15.05.2019).

Naito, K., Takagi, T., Kubota, H., Maruyama, T. (2017). Multi-body dynamic coupling mechanism for generating throwing arm velocity during baseball pitching. Human Movement Science, 54, 363-376. DOI: 10.1016/j.humov.2017.05.013.

Nuhmani, S., Akthar, N. (2014). Anthropometry and functional performance of elite Indian junior tennis players. Journal of Science, 4 (1), 55-59.

Omar, N. (2016). Technique in overarm throwing. A Doctoral Thesis of the Loughborough University. Retrieved from: https://core.ac.uk/ download/pdf/288360734.pdf (12.09.2018).

Opplert, J., Babault, N. (2018). Acute effects of dynamic stretching on muscle flexibility and performance: an analysis of the current literature. Sports Medicine, 48 (2), 299-325.

Peñailillo, L., Espíldora, F., Jannas-Vela, S., Mujika, I., Zbinden-Foncea, H. (2016). Muscle strength and speed performance in youth soccer players. Journal of Human Kinetics, 50 (1), 203-210. DOI: 10.1515/hukin-2015-0157.

Pfeiffer, K.A., True, L., Martin, E., Siegel, S.R., Branta, C.F., Haubenstricker, J., Seefeldt, V. (2020). Methods of the Michigan State University Motor Performance Study. Journal of Measurement in Physical Education and Exercise Science, 1-7. DOI: 10.1080/1091367X.2020.1774888.

Rahnama, N., Lees, A., Bambaecichi, E. (2005). Comparison of muscle strength and flexibility between the preferred and non-preferred leg in English soccer players. Ergonomics, 48 (11-14), 1568-1575. DOI: 10.1080/00140130500101585.

Reilly, T., Williams, A.M., Nevill, A., Franks, A. (2000). A multidisciplinary approach to talent identification in soccer. Journal of Sports Sciences. DOI: 10.1080/02640410050120078. 
Rodríguez-Lorenzo, L., Olmo, M.F., Sánchez-Molina, J.A., Martín-Acero, R. (2018). Kicking Ability and Kicking Deficit in Young Elite Soccer Players. Kinesiology, 50 (2), 194-203.

Rodriguez, A., Sanchez, J., Rodriguez, J., Villa, J. (2016). Effects of seven weeks of static hamstring stretching on flexibility and sprint performance in young soccer players according to their playing position. The Journal of Sports Medicine and Physical Fitness, 56 (4), 345-351.

Saha, P., Nandy, P., Bandyopadhyay, A. (2018). Performance oriented upper arm anthropometric measurements in dominant endomorph, mesomorph and ectomorph (9-11 years) trained male tennis players. International Journal of Yogic, Human Movement and Sports Sciences, 3 (1), 1097-1102.

Saha, S., Kundu, B., Mondal, S. (2014). Positional differences in morphology, somatotype and body composition characteristics in university level Indian footballers. Journal of Trainology, 3 (1), 35-40. DOI: 10.17338/trainology.3.1_35.

Sayers, S., Harackiewicz, D., Harman, E., Frykman, P., Rosenstein, M. (1999). Cross-validation of three jump power equations. Medicine \& Science in Sports \& Exercise, 31 (4), 572-577. DOI: 10.1097/00005768-199904000-00013.

Slimani, M., Nikolaidis, P.T. (2019). Anthropometric and physiological characteristics of male soccer players according to their competitive level, playing position and age group: A systematic review. Journal of Sports Medicine and Physical Fitness. DOI: 10.23736/S0022-4707.17.07950-6.

Spector, P.E. (2019). Do Not Cross Me: Optimizing the Use of Cross-Sectional Designs. Journal of Business and Psychology. DOI: 10.1007/s10869-018-09613-8.

Sportu, I., Nikolaidis, P.T. (2018). Leg strength and power in Polish striker soccer players. Acta of Bioengineering and Biomechanics, 20 (2), 109-116. DOI: 10.5277/ABB-01066-2017-02.

Sylejmani, B., Maliqi, A., Gontarev, S., Haziri, S., Morina, B., Durmishaj, E., Bajrami, A. (2019). Anthropometric Characteristics and Physical Performance of Young Elite Kosovo Soccer Players. International Journal of Morphology, 37 (4), 1429-1436. DOI: 10.4067/S0717-95022019000401429.

Wilson, R.S., David, G.K., Murphy, S.C., Angilletta Jr, M.J., Niehaus, A.C., Hunter, A.H., Smith, M.D. (2017). Skill not athleticism predicts individual variation in match performance of soccer players. Proceedings of the Royal Society B: Biological Sciences, 284 (1868), 20170953. DOI: 10.1098/rspb.2017.0953.

Zouhal, H., Abderrahman, A.B., Dupont, G., Truptin, P., Le Bris, R., Le Postec, E., Coppalle, S., Ravé, G., Brughelli, M., Bideau, B. (2018). Laterality Influences Agility Performance in Elite Soccer Players. Frontiers in Physiology, 9 (June), 1-8. DOI: 10.3389/ fphys.2018.00807.

Cite this article aS: Mensah, T.K., Moses, M.O., Domfeh, C. (2020). Anthropometric and Motor Performance Characteristics of Male Soccer Players in Public Universities. Central European Journal of Sport Sciences and Medicine, 4 (32), 15-25. DOI: 10.18276/cej.2020.4-02. 